\title{
IFE, 23 años
}

\section{José Woldenberg*}

\section{Sumario:}

I. Fundación. Necesidad

II. La confianza, misión fundamental

III. Los principios

IV. Época de novedades

V. Servicio profesional electoral

VI. La germinal democracia mexicana

* Profesor en la Facultad de Ciencias Políticas y Sociales de la UNAM; ex consejero presidente del IFE. 
Quiero agradecer la invitación a Marco Antonio Baños, Lorenzo Córdova, María Marván y Benito Nacif, a quienes aprecio y respeto. Valoro, y mucho, lo que han realizado en tiempos difíciles y plagados de incomprensión. Tengo sentimientos encontrados al comparecer el día de hoy ante ustedes, pero por supuesto que de eso no hablaré. Gracias a todos ustedes por su presencia.

\section{Fundación. Necesidad}

En 1990 se funda el IFE. Su nacimiento no se puede explicar sin lo que había sucedido en el terreno electoral dos años antes.

En 1988 México vivió unas elecciones realmente competidas. No obstante, ni las instituciones, ni las normas ni los operadores políticos estaban capacitados para procesar de manera limpia los resultados. Puede decirse, como en los malos chistes, que en aquellas jornadas tuvimos, como país, dos noticias: una buena y una mala. La buena: que la sociedad mexicana, su diversidad política e ideológica, había forjado referentes partidistas implantados y competitivos. Que esa sociedad no cabía más bajo el manto de un solo partido, una sola ideología, una sola organización. La mala: que los órganos electorales existentes no solo resultaban parciales, sino que eran incapaces de ofrecer garantías de integridad y transparencia no solo a los competidores, sino a la sociedad toda.

Por eso, desde su fundación, la tarea fundamental del IFE fue la de construir confianza en el único método que ha inventado la humanidad para que una comunidad masiva, compleja y contradictoria, como lo es México, pueda expresarse, recrearse, competir y convivir de manera institucional y pacífica: las elecciones. Se contaba ya entonces con un piso común nada despreciable: todas las corrientes políticas medianamente significativas aceptaban $-\mathrm{y}$ aceptan - que la única vía legítima para ocupar los cargos ejecutivos y legislativos es la vía electoral.

La reforma de 1977 ya había abierto las puertas para que corrientes políticas relevantes, a las cuales se les mantenía artificialmente marginadas del mundo electoral, pudieran incorporarse a él. A través del registro condicionado empezaron a aparecer en las boletas diversos partidos: Comunista Mexicano, Demócrata Mexicano, Socialista de los Trabajadores, Revolucionario de los Trabajadores, Socialdemócrata, Mexicano de los Trabajadores, Socialista Unificado de México, Mexicano Socialista. Pero esos nuevos partidos, y quienes ya desde antes contaban con registro, no 
debían ni podían conformarse solo con participar, y demandaban y con razón, garantías de imparcialidad en la conducción de las contiendas.

De hecho, la reforma de 1977 había sido la respuesta estatal a la enorme conflictividad que se vivía en los años setenta en el país. Recordemos: luego de la paranoica represión al movimiento estudiantil de 1968, se vivieron agudos conflictos en las universidades públicas, una ola nueva de invasiones de tierras, la llamada insurgencia sindical que buscaba democratizar los sindicatos o crear algunos nuevos, apareció una guerrilla urbana y otra rural, se multiplicaron las publicaciones independientes y los proyectos para fundar nuevos partidos, y sin embargo, en 1976 México asistió a unas elecciones federales en cuya boleta para elegir presidente de la República aparecía una sola opción: la del licenciado José López Portillo, apoyado por el PRI, el PPS y el PARM. El PAN, la oposición tradicional, no pudo en su convención lanzar candidato porque ninguno de los precandidatos logró el 80\% de los votos necesarios, como lo estipulaban sus estatutos, para convertirse en su abanderado. El Partido Comunista, aunque postuló al combativo sindicalista Valentín Campa, carecía de registro y por ello los sufragios para su candidato no se computaron. Total: un desfase absoluto entre el mundo institucional electoral —un mundo de unanimidades - y la enorme conflictividad política y social que cruzaba al país.

En buena hora, la reforma de 1977 se hizo cargo de esa situación e intentó construir canales de comunicación entre esos dos Méxicos. Creo que con esa reforma se inauguró el lento, zigzagueante, pero promisorio proceso de transición democrática. Un proceso que visto en retrospectiva logró desconstruir un sistema autoritario y construir una germinal democracia.

En 1989-90, fechas en las que se diseña el IFE, México ha asimilado las primeras derivaciones de aquella operación reformadora de 1977. Vivía el país una dinámica que se autoalimentaba. Partidos cada vez más implantados generaban un incremento en la competitividad y esa competencia incrementada reforzaba la centralidad de los partidos. Pero ambos fenómenos anudados reclamaban que las elecciones fueran limpias y transparentes, que la voluntad popular se respetara.

\section{La confianza, misión fundamental}

Entonces, repito: si hubiese que definir en una palabra la misión del Instituto Federal Electoral, esa sería construir confianza. El IFE tenía y tiene como misión lograr la confianza en las elecciones. Dado el déficit mo- 
numental que en ese materia acarreaba el país, el IFE debía coadyuvar de manera significativa a que los partidos, candidatos, analistas, organizaciones no gubernamentales, medios de comunicación y ciudadanos, confiaran en la vía electoral como la fórmula por excelencia para que la diversidad política que cruza al país pudiera convivir y competir de manera institucional, ordenada y pacífica.

Pero la confianza no se decreta ni se edifica a través de un acto de magia. La confianza - insisto- es una construcción. Día a día, acuerdo tras acuerdo, resolución tras resolución, resultado tras resultado, se va forjando la confianza, y por supuesto una mala decisión tiende a erosionar a la misma. Si la confianza se pudiera dictar, si apareciera de la noche a la mañana, si fuera una aparición, todo sería fácil. No obstante, como se trata de una auténtica cimentación social, su edificación no es sencilla.

México estuvo inmerso en un proceso de transición democrática. El formato (casi) monopartidista que había ordenado la vida política del país durante largas décadas fue substituido por un sistema de partidos que expresa la pluralidad política e ideológica de la sociedad mexicana. Las elecciones sin competencia fueron un expediente del pasado y la competitividad a lo largo de ese trayecto se encontraba al alza demandando imparcialidad de los jueces en la contienda y condiciones equitativas para la misma. El mundo de la representación política dejó de ser monocolor y paulatinamente una diversidad de fuerzas colonizó las instituciones estatales. En ese contexto resultaba necesaria (imprescindible) una autoridad que de manera inequívoca ofreciera garantías de imparcialidad a todos los contendientes.

Y el objetivo, más allá de ganadores y perdedores circunstanciales, era naturalizar a la vía electoral como la fórmula reconocida por todos para arribar a los cargos de gobierno y legislativos. Es natural que a los ciudadanos les interese, sobre todo, quienes son los ganadores, pero a las autoridades electorales les importa por sobre todas las cosas que el proceso transcurra de buena manera, sin incidentes mayores, apegado a la legalidad y que al final todas las fuerzas políticas reconozcan los resultados.

Y para alcanzar ese objetivo, todas las áreas del Instituto se orientaron en esa dirección. A lo largo de los años aparecieron innumerables novedades, las cuales sirvieron para ratificar que el IFE estaba capacitado para organizar elecciones imparciales y equilibradas. Se trató de una etapa en la que muchos eventos se produjeron "por primera vez". Así, en 1997, "por primera vez” ningún partido político obtuvo mayoría absoluta de diputados en la Cámara, y "por primera vez" se realizaron elecciones para designar al jefe de gobierno del Distrito Federal (como entonces no 
existían autoridades electorales locales en la capital, se le encomendó al IFE por única ocasión la organización de esos comicios). "Por primera vez" en el año 2000 se produjo la alternancia en el Ejecutivo Federal por la vía electoral, y "por primera vez" en el Senado desapareció la mayoría absoluta de un partido político.

Por supuesto esas nuevas realidades políticas no las construyó el IFE, sino los ciudadanos votando, pero el IFE demostró que era una autoridad capaz de asimilar cualquier resultado electoral, beneficiara a quien beneficiara.

Esos resultados coadyuvaron a remontar la desconfianza y a construir confianza en el único método que le permite a una sociedad compleja que sus fuerzas políticas convivan y compitan de manera institucional.

Luego, también hay que apuntarlo, agudos y polarizados conflictos poselectorales erosionaron la confianza construida. Pero el Instituto jamás dejó de seguir afinando sus rutinas para ofrecer las necesarias garantías de imparcialidad, transparencia y equidad en la contienda.

\section{Los principios}

Para alcanzar la confianza las labores del IFE se sustentaron en valores fundamentales que se encuentran en la propia Constitución y que aquí solamente enuncio, pero que vale la pena recordar ahora que el IFE, en el mejor de los casos, se transformará en el Instituto Nacional Electoral.

Autonomía. Se trata de la capacidad del IFE para tomar sus decisiones a través de sus circuitos internos de deliberación y acuerdo, sin la interferencia de agentes externos. La autonomía debe preservarse y fortalecerse día a día, no basta con que se encuentre consagrada en la Constitución o la ley. Todas las políticas, todos los programas, todas las decisiones, se deben tomar en el IFE. Cierto, los partidos y el Poder Legislativo tienen representantes en el Instituto, y legítimamente pueden y deben abogar por sus intereses. Pero es menester que gobiernos y partidos entiendan que los consejeros no son ni deben ser sus correas de trasmisión y que solo de esa manera el Instituto puede ser capaz de organizar y arbitrar los procesos electorales. Precisamente porque gobiernos y partidos tienen un enorme poder, precisamente porque entre ellos pueden existir querellas, precisamente porque sus intereses no siempre están alineados, es necesario un arbitraje por encima de sus intereses y pasiones. Y ese arbitraje para ser tal requiere que se ejerza invariablemente la autonomía. 
Legalidad. El ancla fundamental de una autoridad se encuentra en la ley. Ninguna buena voluntad puede estar por encima de las normas. El apego a la ley sirve para acabar con la posible discrecionalidad en el comportamiento de la autoridad, pero sobre todo ofrece garantías a los partidos y candidatos de que jamás encontrarán una autoridad caprichosa. La ley es sinónimo de certeza. Gracias a ella, el IFE contó con un marco para su actuación, sus facultades y límites. El Cofipe, un código de procedimientos, inyectó certeza en los plazos, las resoluciones, las vías para impugnar. Fue brújula cierta para el Instituto y para todos los actores, incluyendo los ciudadanos. Por eso (me) preocupan los grados de discrecionalidad con los cuales contará el nuevo Consejo General del Instituto Nacional Electoral (pero eso, por lo pronto, es harina de otro costal).

Imparcialidad. El IFE es un organizador y un árbitro y por eso debe actuar por encima de los competidores y más allá de sus intereses. Y no es -o debiera ser- una vocación difícil. Por el contrario, dado que el Instituto tiene la misión de asentar la competencia electoral regulada entre una pluralidad de partidos, debería resultar sencillo - natural- no alinearse a ninguno de ellos. A los competidores les importa, por sobre todo, el resultado; al árbitro el desarrollo correcto de la contienda. México es la casa común de todos los partidos, de todas las corrientes político e ideológicas que la habitan, y no hay misión más incluyente y estratégica que lograr que ellas encuentren un espacio cierto para su convivencia y su competencia. Los partidos son por definición parciales, el IFE por el contrario encuentra en la imparcialidad su razón de ser.

Certeza. Los partidos y los ciudadanos deben saber que ante situaciones iguales o similares, la autoridad actuará de la misma manera. Es decir, que existe un mismo metro para medir la conducta de los partidos, los candidatos, los medios, etcétera. Esa certeza es imprescindible porque las elecciones portan consigo una enorme incertidumbre. Grandes constelaciones políticas se despliegan en torno a los partidos y sus candidatos, y las pasiones que desencadenan no son pocas. Se desatan expectativas y ensueños, se anudan intereses y convergencias, se hacen "apuestas" grandes y ambiciosas. En una palabra, las contiendas electorales generan tensión, incertidumbre, nerviosismo. En ese marco de la autoridad electoral y la ley deben irradiar certeza y más certeza. Y esa es la única manera como se logra la confianza.

Objetividad. Más allá de los dimes y diretes, de las campañas de opinión, de las acusaciones mutuas, que son connaturales a los procesos electorales, la autoridad debe resolver conforme a elementos objetivos, mensurables, "incontrovertibles" (hasta donde esto es posible), intentan- 
do desterrar los juicios subjetivos, inasibles, nebulosos. Eso que la Constitución llama objetividad es la mejor manera de inyectar confianza.

Y creo que esos principios guiaron auténticamente la labor del IFE, que como toda labor humana por supuesto está y debe estar sujeta a la crítica.

\section{IV. Época de novedades}

Lo cierto es que para los que laboramos o laboran hoy en el IFE la Institución fue y es una casa modelada por la intensidad de los asuntos que están en su agenda, pero es un hogar con un enorme sentido. Reitero: intensa porque se trabaja en medio de la tensión que es propia a las contiendas electorales, pero con un enorme sentido, porque en el IFE, quizá como en ninguna otra institución, se aprende que estamos, en buena hora, condenados a vivir en y con una pluralidad de opciones que es donde reside la riqueza del país. Esa diversidad de diagnósticos y programas, de ideologías e intereses, de sensibilidades y horizontes, es la que colorea el espacio público y a la que el IFE - entre otros- debe ofrecer garantías.

Los añejos y nuevos autoritarismos, de todo cuño, ensueñan con homogenizar lo que es diverso, con alinear lo que es centrífugo, con clausurar y no con ofrecer cauce a la pluralidad. Pues bien, la misión del IFE se encuentra en las antípodas de esas pulsiones: el Instituto se fundó para que la variedad de opciones políticas que existen en México puedan pronunciarse, reproducirse, coexistir y rivalizar de manera pública, pacífica e institucional.

En el IFE muchos de los mecanismos, dispositivos, rutinas y procedimientos electorales sucedieron por primera vez hasta convertirse en parte de nuestro paisaje. Quiero recordar algunos de ellos ahora.

Gracias al IFE por primera vez se votó con una credencial con fotografía, para una mejor identificación de los votantes.

Gracias al IFE por primera vez se imprimieron las listas nominales de electores con fotografía y se les entregaron a los partidos, para que pudieran checar el padrón y en el momento de los comicios a los votantes.

Gracias al IFE, por primera vez...

...Se insacularon a los funcionarios de casilla, para ofrecer garantías de imparcialidad en la recepción y cómputo de los votos.

...Se multiplicaron los programas de educación cívica democrática para socializar los valores y principios que la animan.

...Se organizaron votaciones para los niños con la finalidad de inculcarles la noción de que son sujetos de derechos. 
...Se utilizó una tinta indeleble realmente indeleble, para evitar que un elector pudiera sufragar dos veces.

...Se fiscalizaron las finanzas de los partidos, para conocer al detalle sus ingresos y sus gatos, para saber si no sobrepasaban los topes de campaña y si sus fuentes de financiamiento eran lícitas.

...Se construyó una política internacional digna de tal nombre que nos ayudó a presentarle el sistema electoral al mundo y a aprender de lo que sucede en otras latitudes.

...Se construyeron mamparas para que a la hora de votar el elector estuviera en absoluta soledad, de tal suerte que si hubiese sido coaccionado o presionado tuviera garantías de que nadie iba a conocer el sentido de su voto.

...Se diseñaron boletas en papel seguridad, foliadas en el lomo, con el municipio donde debían ser utilizadas, para evitar su tráfico irresponsable.

...Se monitoreó el comportamiento de los noticieros de radio y televisión y los resultados fueron dados a conocer al público, generando un contexto de exigencia a los medios y tratando de construir condiciones equitativas para la contienda.

...Se entregaron lineamientos a los concesionarios de la radio y la televisión buscando que la cobertura de las campañas fuera equilibrada y objetiva.

...Se administraron los llamados tiempos del Estado no solo a nivel federal sino también en las elecciones locales, cumpliendo con los preceptos legales y logrando un piso de equidad en los medios.

...Se puso en pie un programa de resultados electorales preliminares para que la misma noche de la elección los ciudadanos contaran con información oficial cierta y desagregada.

...Se realizaron conteos rápidos que ayudan a conocer las tendencias finales de la votación y que se constituyeron en un referente para otros conteos rápidos.

...Se registraron las metodologías de las encuestas y conteos rápidos que, realizados por particulares, fueran a darse a conocer, para cerrarle el paso a ejercicios fraudulentos en esos terrenos.

...Se construyó un mecanismo para hacer accesible y transparente la información pública de los partidos, dado que los mismos son entidades de interés público y los ciudadanos deben tener acceso a lo que en ellos sucede.

...Se capacitaron millones de funcionarios de casilla, ciudadanos generosos que comprendieron que realizarían una estratégica tarea para la convivencia civilizada, con la finalidad de garantizar el recuento escrupuloso de los votos. 
...Se diseñó y organizó un servicio civil de carrera que es, sin duda, la columna vertebral del Instituto.

Y tantas otras que por supuesto no voy a enumerar, para no cansarlos demasiado. Sé que he enunciado programas e iniciativas de muy diverso calado, pero lo hago solo para ilustrar mi dicho: el IFE es o fue una institución que nunca se cansó de innovar.

Pero el listado anterior debe servirnos sobre todo para una cosa: si hoy tenemos elecciones competidas, fenómenos de alternancia en todos los niveles, coexistencia de la diversidad política en las instituciones del Estado, ejercicio de libertades, es porque el eslabón fundamental e intransferible de la democracia, las elecciones, se construye en el IFE paso a paso con imparcialidad, profesionalismo y esmero. Esa es la herencia del IFE. La de los miles de hombres y mujeres que con su trabajo diario, eficiente y puntual han forjado el prestigio de una institución que ha servido a México, a su diversidad política.

\section{Servicio profesional electoral}

Ya casi para terminar quiero decir algo sobre el servicio profesional electoral y todos aquellos que laboran en el Instituto. A fin de cuentas las instituciones están conformadas por hombres y mujeres y ellos son los responsables de su actuación.

Desde su diseño inicial, se pensó que el IFE debía contar con un servicio civil de carrera: un cuerpo de funcionarios profesionales que garantizaran la eficiencia y la imparcialidad de la autoridad. Hasta ese entonces, la inmensa mayoría de los funcionarios que trabajaban en la organización de las elecciones eran - permítanme la palabreja - "de temporal". Es decir, laboraban en el proceso y luego debían buscar acomodo en alguna otra dependencia. Pues bien, el gran cambio en el IFE fue que de su fundación en adelante se construyó una carrera profesional dentro del Instituto. Se trataba de que los funcionarios fueran leales a la institución (y no a algún poder externo), a cambio la institución les ofrecería una vía para su desarrollo y estabilidad laboral.

Se diseñaron mecanismos de ingreso, de evaluación, de promoción, mecanismos para obtener la permanencia en el trabajo. En un Estatuto se reguló la carrera dentro de la institución. Y hoy, el IFE puede decir, con orgullo, que su columna vertebral la integran centenas, miles de funcionarios que han probado con su trabajo, dedicación y experiencia que 
cada uno de los eslabones del proceso electoral está en manos de auténticos conocedores de la materia. No más improvisación, no más incertidumbre. No. Hombres y mujeres que han probado una y otra vez que en materia de organización, capacitación, registro de electores, gestión de las prerrogativas de los partidos, fiscalización, administración, educación cívica, resultados preliminares, conteos rápidos, y súmenle ustedes, cuenta con un capital insustituible.

Esos hombres y mujeres, integrantes del servicio profesional electoral, y aquellos trabajadores que hacen otras labores, son la mejor y más preciada herencia del IFE. Espero sinceramente que esa herencia sea rescata$\mathrm{da}$, asumida, integrada por el nuevo Instituto Nacional Electoral. Porque el país no está como para que en esta materia empecemos de nuevo de cero, como sí lo hizo, y lo hizo bien, el Instituto Federal Electoral.

Además, en los últimos meses la máxima autoridad del Instituto, su Consejo General, no ha estado integrado de manera completa. Y ello ha sido así no por el Instituto. No obstante, los cuatros consejeros, rotándose la presidencia, junto con el secretario ejecutivo, han dado una lección de profesionalismo, templanza y certidumbre. Hago votos porque esa experiencia tampoco se dilapide y en el INE, que nacerá dentro de poco, se recupere y conjugue con "sangre nueva".

\section{La germinal democracia mexicana}

He sostenido que México vivió una auténtica transición democrática: pasamos de un sistema de partido casi único a un sistema de partidos plural y equilibrado, de elecciones sin competencia a elecciones altamente competidas, y de un mundo de la representación habitado por (casi) una sola fuerza política a un escenario en el que convive de manera equilibrada una pluralidad de organizaciones.

Hay quien dice con un dejo de desprecio que se trató meramente de una transformación electoral. Quien eso afirman no entienden la centralidad de las elecciones ya no digamos en los sistemas democráticos sino en la vida política toda. Porque en el momento en que México contó con un sistema plural de partidos y con elecciones auténticas, todo el engranaje constitucional democrático se puso en acción. Transitamos de una presidencia de la República omnipotente a una presidencia acotada; de un Congreso subordinado a la voluntad presidencial a un Congreso que se mueve por una dinámica propia alimentada por un equilibrio de 
fuerzas novedoso; de un centralismo arraigado a un federalismo todavía contrahecho pero auténtico, y hasta la Suprema Corte que durante décadas jugó un papel más bien secundario en materia política, hoy tiene un papel central cuando desahoga controversias constitucionales o acciones de inconstitucionalidad.

Y para que ello fuera necesario se requirió de una institución como el IFE. De hecho, el IFE nació en los momentos estelares de esa transición: cuando las fuerzas políticas diversas demostraron que no cabían bajo el añejo formato y demandaron imparcialidad y transparencia en las contiendas. Esa transición fue gradual, se inició lentamente en 1977, y como una pequeña bola de nieve al rodar se convirtió en un auténtico alud. Y ya para 1988 mostró que el México plural que coexistía en la sociedad se expresaba también en las urnas. En 1990 - repito- se creó el IFE y luego de las primeras tres elecciones que organizó y por supuesto de la profunda reforma electoral de 1996, podemos afirmar que concluyó la multicitada transición.

A partir de entonces México vive en democracia. Una democracia germinal, inestable, compleja, que ha desatado innumerables reclamos y que se reproduce en unas condiciones socio-económicas - en un océano de desigualdades - nada propicias. Pero democracia al fin.

Y si no me creen, les ofrezco los siguientes datos que ustedes conocen:

Cuando nació el IFE todos los presidentes habían sido de un solo partido. Con el IFE hemos vivido dos alternancias.

Cuando nació el IFE el PRI tenía mayoría absoluta en la Cámara de Diputados, hoy en dicha Cámara convive una pluralidad equilibrada, y el diálogo, la negociación y el acuerdo son necesarios.

Cuando nació el IFE la Cámara de Senadores tenía 64 integrantes, 60 eran del tricolor y solo 4 de la oposición (del PRD, para ser exactos), mientras hoy es un espacio donde se expresa y acuerda una diversidad nivelada de corrientes políticas.

Por supuesto, nada de eso lo hizo el IFE. Ello es fruto de una ciudadanía que porta sensibilidades, intereses e ideologías distintas. Pero para que eso fuera posible se requirió del Instituto que hoy despedimos.

Repito: México vive en democracia, la transición ha quedado atrás, y la democracia requiere de autoridades electorales autónomas, imparciales, apegadas a la legalidad, generadoras de certeza, comprometidas con la objetividad, profesionales. Como lo ha sido el IFE. Que así sea también el INE. Para bien del país y de la coexistencia civilizada de su diversidad política. 